\title{
Electrohydrodynamic jet printing of PZT thick film micro-scale structures
}

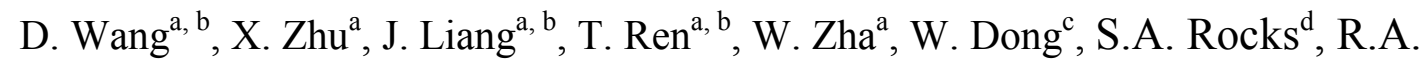

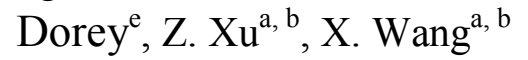 \\ ${ }^{\mathrm{a}}$ Key Laboratory for Micro/Nano Technology and System of Liaoning Province, \\ Dalian University of Technology, Dalian, 116024, China \\ ${ }^{\mathrm{b}}$ Key Laboratory for Precision and Non-traditional Machining Technology of Ministry \\ of Education, Dalian University of Technology, Dalian, 116024, China \\ ${ }^{\mathrm{c} C o l l e g e}$ of Electronic Science and Technology, Dalian University of Technology, \\ Dalian, 116024, China \\ ${ }^{\mathrm{d} C}$ ranfield University, Bedfordshire, MK43 0AL, UK \\ ${ }^{\mathrm{e}}$ University of Surrey, Surrey, GU2 7XH, UK
}

\begin{abstract}
This paper reports the use of a printing technique, called electrohydrodynamic jet printing, for producing PZT thick film micro-scale structures without additional material removing processes. The PZT powder was ball-milled and the effect of milling time on the particle size was examined. This ball-milling process can significantly reduce the PZT particle size and help to prepare stable composite slurry suitable for the E-Jet printing. The PZT micro-scale structures with different features were produced. The PZT lines with different widths and separations were fabricated through the control of the E-Jet printing parameters. The widths of the PZT lines were varied from $80 \mu \mathrm{m}$ to $200 \mu \mathrm{m}$ and the separations were changed from $5 \mu \mathrm{m}$ to $200 \mu \mathrm{m}$. In addition, PZT walled structures were obtained by multi-layer E-Jet printing. The E-Jet printed PZT thick films exhibited a relative permittivity $\left(\varepsilon_{\mathrm{r}}\right)$ of $\sim 233$ and a piezoelectric constant $\left(\mathrm{d}_{33, \mathrm{f}}\right)$ of $\sim 66 \mathrm{pC} \mathrm{N}^{-1}$.
\end{abstract}

Keywords: Electrohydrodynamic jet; printing; PZT; thick film

\section{Introduction}

Micro-electromechanical systems (MEMS) containing active piezoelectric components are of great importance in the fields of sensors, actuators and transducers [1-3]. The most commonly used piezoelectric material is lead zirconate titanate (PZT) because of its high piezoelectric constant, relative permittivity and electromechanical coupling coefficient [4]. Recently, PZT thick film has attracted considerable attention because sensing signals, strains and actuating forces are closely related to the film thickness [5-7]. Consequently, piezoelectric thick films $(>5 \mu \mathrm{m})$ are favourable for the MEMS devices requiring large strains, large actuating forces and high frequency such as micro-power harvesters [8], micro-actuators [9] and high resolution piezoelectric ultrasonic transducers [10]. However, there are two key issues need to be overcome for realizing the function of these PZT thick film MEMS devices. One is the fabrication of PZT thick films, the other is the patterning of PZT thick films.

Conventional thin-film technology such as sputtering and chemical vapor deposition (CVD) need long operating time and multiple deposition passes for the fabrication of micrometer-sized PZT films [11]. Machining and bonding of bulk PZT has a 
significant difficulty of producing films smaller than $100 \mu \mathrm{m}$ due to the high brittleness of the film at this thickness [12]. Various techniques for the deposition of PZT thick films have been investigated and showed considerable capability, such as screen printing [13], aerosol deposition [14] and composite film technology [15].

However, in order to satisfy the performance requirement of this type of MEMS device it is necessary to pattern the PZT thick films with desired structures. The current high-performance PZT MEMS devices normally require feature sizes at a few micrometer scale combined with high side wall angle [16], which is still a technical challenge. The commonly used method to pattern PZT thick film structures is screen printing $[17,18]$. During the screen printing process an ink is forced though a fine mesh to deposit it onto the desired substrate. The film is then dried and sintered at elevated temperatures to yield a dense thick film and a desired crystalline structure. This method has the advantage of patterning the film directly by selectively masking certain areas of the mesh. This method is also suitable to produce PZT thick film structures at a large scale and is compatible with different substrates. However, the limitation of this method is that the maximum resolution depends on the size of the mesh used. The mesh fabrication is usually associated with photolithography, etching and laser cutting technologies. These additional multi-step fabrication processes not only increase the complexity of screen printing but also limit the mesh size and printing resolution.

Dry etching and wet etching have also been used for patterning PZT thick film structures. Dry etching allows high side wall angle due to the anisotropic nature of the etching process [19]. However, dry etching techniques are slow and need dedicated machines when etching PZT to prevent cross contamination [20]. This requires extremely long processing time and high associated expense. Wet etching of PZT is isotropic in nature so it is only possible to obtain a 1:1 ratio between undercut and thickness during the pattering of PZT thick film [21]. The degree of undercutting for wet etching of thick films is generally greater due to a higher degree of residual porosity in the thick films formed during the consolidation of ceramic particles through the action of heat. During etching etchant can enter these pores and accelerate the undercutting rate. In addition, hazardous solutions such as hydrofluoric acid are normally used in chemical wet etching, which need special protection equipment and hazardous liquid treatment process. In addition, the etching materials are normally difficult to be removed after etching and will remain inside the PZT thick film [22, 23], which will result in the decline of the PZT properties.

Electrohydrodynamic jet (E-Jet) printing provides a new way for forming PZT thick film micro-scale structures. E-Jet makes use of electrical and mechanical forces to form an ink jet and drive flow of inks out of the needle and onto a target substrate. The distinct advantage of this method is that the jet diameter is much smaller than the needle size, which can significantly reduce the risk of needle blockage, especially when the high viscous liquid and suspension containing particles were used. In this process even very small ion concentrations in the ink are sufficient to enable this E-Jetting happen. An electrical conductivity could be as low as $10^{-11} \mathrm{~S} \mathrm{~m}^{-1}$ [24]. Viscosity of higher than $1000 \mathrm{mPa}$ s was also reported for obtaining stable E-Jetting process [25]. The major working parameters in E-Jet printing process are applied voltage, flow rate and needle-substrate distance. The applied voltage is usually in the range of a few kilovolts. The flow rate of the ink at the outlet of needle can be smaller than $1.0 \times 10^{-14} \mathrm{~m}^{3} \mathrm{~s}^{-1}$ in order to print the feature sizes at sub-micrometer scale. 
Needle-substrate distance is normally kept smaller than millimeter scale in order to focus the electric field force and reduce the diffusion of satellite droplets. Recently, E-Jet printing has been used for pattering various ceramic structures, such as grid $\mathrm{ZnO}$ nanofibers [26], $\mathrm{SiCN}$ micro pentagram structures [27] and $\mathrm{Al}_{2} \mathrm{O}_{3}$ nanoparticle patterns [28].

In this work, E-Jet printing technique combined with the PZT composite slurry was used to pattern PZT thick film micro-scale structures, which enable the formation of the PZT thick film structures without additional material removing process. The characteristics of the printed micro-scale structures and their properties were examined and analyzed.

\section{Experimental details}

\subsection{Preparation and characterisation of PZT slurry}

In order to examine the effect of the milling time on the PZT particle size the PZT powder (Pz26, Ferroperm Piezoceramics, MEGGITT, Denmark) was ball-milled with distilled water using a high energy ball mill (QM-3SP2, Nanjing University Instrument Plant, China) for different times. The PZT power (Pz26) is a hard doped PZT with a nominal chemical composition of $\mathrm{Pb}_{1.1}\left[\mathrm{Nb}_{0.02} \mathrm{Sb}_{0.02} \mathrm{Mn}_{0.02}\left(\mathrm{Ti}_{0.48} \mathrm{Zr}_{0.52}\right)_{0.94}\right] \mathrm{O}_{3}$. After every $10 \mathrm{~h}$ of milling the PZT particles were analyzed using a scanning electron microscope (JSM-6360LV, JEOL Ltd, Japan). The mean PZT particle size after ball-milling was also measured using a particle size analyzer (Zetasizer Nano ZS 90, Malvern Instruments, UK). The PZT sol was prepared by mixing of titanium (IV) isopropoxide ( $99.99 \mathrm{wt} . \%$ purity), zirconium (IV) propoxide (76 wt.\% in 1-propanol), lead (II) acetate trihydrate, 1-propanol (99.7 wt.\%) and glacial acetic acid (99.8 wt.\%), which has the final chemical stoichiometric ratio of metal ions of $\mathrm{Pb} 1.10: \mathrm{Zr} \mathrm{0.48:} \mathrm{Ti} \mathrm{0.52.} \mathrm{The} \mathrm{details} \mathrm{of} \mathrm{the} \mathrm{components} \mathrm{and}$ preparation routes of the PZT sol were described in our previous work [29]. The PZT slurry used in this work was prepared by ball-milling of $10 \mathrm{~g}$ of PZT powder, $14.2 \mathrm{ml}$ of PZT sol and $0.2 \mathrm{~g}$ of dispersant KR 55 (Ken-React Lica 38, KenRich, US) and 100 $\mathrm{g}$ of zirconia balls for 40 hours. The KR 55 dispersant is a type of organo titanates with a chemical name of Titanium IV tetrakis \{2, 2-bis (2-propenyloxy) methyl-1-butanolato-O 3 adduct 2 moles (ditridecyl phosphito-O), dihydrogen. The solid load for this slurry is $48.6 \%$. The details of the components and ball-milling parameters of the PZT slurry are shown in Table 1. The viscosity of the PZT slurry was measured using a rotational viscometer with a shear rate range of $176 \mathrm{~s}^{-1}-3550 \mathrm{~s}^{-1}$ (NDJ-79, Shanghai Pingxuan Scientific Instrument, China). The surface tension was measured by a contact angle meter (Krüss DSA 100, Krüss GMBH, Hamburg, Germany). The electrical conductivity was measured by a conductive meter (DDS-307, Shanghai INESA Scientific Instrument, China). The relative permittivity was obtained by a precision impedance analyser (4294A, Agilent Technologies, Santa Clara, US). The PH was measured by a $\mathrm{pH}$ meter (PHS-3C, Shanghai INESA Scientific Instrument, China). The properties of the PZT slurry are shown in Table 2. The material properties suitable for obtaining a stable cone-jet mode used in E-Jet printing require an electrical conductivity of more than $10^{-11} \mathrm{~S} \mathrm{~m}^{-1}$, a surface tension of less than $50 \mathrm{mN} \mathrm{m}^{-1}$ and a viscosity of less than $100 \mathrm{mPa} \mathrm{s}^{-1}$ [24]. It can be seen from Table 2 that the prepared PZT slurry satisfied the requirements for getting a stable cone-jet mode.

\subsection{E-Jet printing of PZT slurry}


Fig. 1 shows the E-Jet printing device, which is mainly comprised of an E-Jet printing needle, a computer controlled $\mathrm{X}-\mathrm{Y}$ movement stage, a high power supply, a syringe pump and a microscopic vision system. This E-Jet printing device was developed in our lab. The needle was connected to the high voltage power supply (Tianjin DongWen High Voltage Power Supply Co., Ltd, China) which was used to provide an electric field between the needle and the ground electrode. The inlet of the needle was connected to the syringe pump (LSP01-2A, LongerPump, Baoding, China), which provides the hydrodynamic force to push the PZT slurry to the outlet of the needle. In this work, the needle has an inner and outer diameter of $0.2 \mathrm{~mm}$ and $0.7 \mathrm{~mm}$, respectively. The E-Jet printing process could be observed in real-time by using the microscopic vision system.

A silicon wafer substrate coated with sputtered $\mathrm{Ti} / \mathrm{Pt}(8 / 100 \mathrm{~nm})$ was used for the E-Jet printing of PZT structures. During printing this Ti/Pt coated wafer was placed on the aluminium plate ground electrode. The stable cone-jet mode was obtained and kept constant throughout the printing process. The widths, gaps and thicknesses of printed PZT lines were varied in order to examine the characteristics of the E-Jet printed PZT micro-scale structures. During the printing of the PZT lines with width variations the flow rate were kept at constant of $1.67 \times 10^{-11} \mathrm{~m}^{3} \mathrm{~s}^{-1}$, the applied voltage was varied between $0.8 \mathrm{kV}$ and $1.3 \mathrm{kV}$ according to the different working distances from $0.3 \mathrm{~mm}$ to $0.5 \mathrm{~mm}$. During the printing of the PZT lines with gap and thickness variations the working distance used was $0.35 \mathrm{~mm}$ and $0.45 \mathrm{~mm}$, respectively, the flow rate was kept at constant of $1.67 \times 10^{-11} \mathrm{~m}^{3} \mathrm{~s}^{-1}$. After printing the PZT lines with width and gap variations were dried at $200{ }^{\circ} \mathrm{C}$ for $60 \mathrm{~s}$ and pyrolysed at $350{ }^{\circ} \mathrm{C}$ for 60 $\mathrm{s}$ using a hotplate to remove the organic components. The completed PZT structures were sintered at $720{ }^{\circ} \mathrm{C}$ for $20 \mathrm{~min}$ in a muffle furnace. The heating rate for this sintering process was $20{ }^{\circ} \mathrm{C} \mathrm{min}{ }^{-1}$. After heating the PZT structures were kept in the furnace for self-cooling to the room temperature. The total sintering duration is $2.5 \mathrm{~h}$. In addition, a large area of PZT thick film was printed using the E-Jet printing, which was used to examine its electric properties. In order to examine the electrical properties of the PZT film a copper electrode with a thickness of $200 \mathrm{~nm}$ and a diameter of $2 \mathrm{~mm}$ was deposited using a Magnetron sputtering apparatus (LAB.18, Kurt J.Lesker, Pittsburgh, USA) on the PZT film surface after sintering. The dielectric property (relative permittivity) was calculated from the capacitance of the film measured using a LCR meter (ZL5, Shanghai Instrument Group, China). The piezoelectric properties $\left(\mathrm{d}_{33}, \mathrm{f}\right)$ were measured using a piezoelectric constant meter (YE2730A, Sinocera, Shanghai, China).

\section{Results and discussion}

\subsection{Ball-milling of PZT powder}

The PZT slurry used in this work was prepared by mixing of PZT sol and PZT powder. The size of the PZT powder has a great effect on the E-Jet printing process since the bigger sized particles are likely to sediment in the PZT slurry and further result in the unstable E-Jet mode. In addition, the smaller PZT particle can lead to better packing and help to improve the performance. In this work the PZT powder was ball-milled with distilled water and the effect of the milling time on its size was examined. Fig. 2a-e show the characteristics of the PZT particles before ball-milled and after ball-milled for $10 \mathrm{~h}, 20 \mathrm{~h}, 30 \mathrm{~h}$ and $40 \mathrm{~h}$, respectively. The average PZT particle size was about $0.8 \mu \mathrm{m}$ before ball-milling. After ball-milled for 10 hours the mean PZT particle size was $0.4 \mu \mathrm{m}$ which is half of that without ball-milling. The 
mean PZT particle size was $0.4 \mu \mathrm{m}, 0.3 \mu \mathrm{m}, 0.25 \mu \mathrm{m}$ and $0.2 \mu \mathrm{m}$ after ball-milled for $10 \mathrm{~h}, 20 \mathrm{~h}, 30 \mathrm{~h}$ and $40 \mathrm{~h}$, respectively. It can be seen that the ball-milling process can significantly reduce the particle size. It can also be found that there is still some big rigid particle residues remained in the powder after ball-milling. Fig. $2 \mathbf{f}$ is the particle size distribution after ball-milling for $40 \mathrm{~h}$, which indicates that the mean particle size is about $200 \mathrm{~nm}$. When the milling time was increased further the PZT particle size has no distinct difference, this indicated that the ball-milling reached its technical limitation.

Based on the above analysis it can be concluded that the ball-milling technique can significantly reduce the PZT particle size. It was also found in our experiments that the sedimentation were likely to happen after simple mixing of PZT powder and PZT sol. Fig. 3a shows the PZT slurry prepared using the simple mixing process and stayed after 30 minutes. It was observed that the sedimentation happened. A stable cone-jet mode should be formed and kept throughout the E-Jet printing process. The sedimentation of slurry will interrupt the stable cone-jet mode and result in the irregular printing feature. Therefore, the ball-milling was applied to prepare PZT slurry. The PZT sol and PZT powder were ball-milled for $40 \mathrm{~h}$ to form the PZT slurry for E-Jet printing. Fig. 3b shows the PZT slurry prepared by ball-milling process and stayed after 10 hours. It can be seen that the PZT particles were well dispersed in the sol and no sedimentation was found for this slurry. This PZT slurry can help to provide stable E-Jet printing process.

\subsection{E-Jet printing of PZT micro-scale structures}

Fig. 4 shows the E-Jet printed PZT lines with width variations. These lines were produced by one layer of E-Jet printing at different working distances from $0.3 \mathrm{~mm}$ to $0.5 \mathrm{~mm}$. It can be seen that these lines are uniform in width. At the working distance of $0.5 \mathrm{~mm}$ the E-Jet printed lines were $200 \mu \mathrm{m}$ in width (Fig. 4a). Fig. $4 \mathbf{b}$ and $\mathbf{c}$ are the surface and cross-section of the printed lines in Fig. 4a. It was observed that the PZT particles were well-arranged and the film presented a close-packed structure. The line thickness is about $1 \mu \mathrm{m}$ for one layer of E-Jet printing (Fig. 4c). Fig. 4d-f show the PZT lines printed at the working distances of $0.45 \mathrm{~mm}, 0.35 \mathrm{~mm}$ and $0.3 \mathrm{~mm}$, respectively. When the working distance was reduced from $0.5 \mathrm{~mm}$ to $0.3 \mathrm{~mm}$, the line width was decreased from $200 \mu \mathrm{m}$ to $80 \mu \mathrm{m}$ (Fig. 4a and d-f). The smaller working distance can reduce the effect of the radial electric field, thus increasing the focus of the jet and reducing the printed feature size. The minimum line width printed was $80 \mu \mathrm{m}$ at the working distance of $0.3 \mathrm{~mm}$ in this work. Smaller distances resulted in a discharge between the needle and substrate and interrupted the printing process. A smaller sized needle can help to reduce the flow rate and reduce the possibility of the discharge phenomenon. However, it was found in this work that the drying of the slurry at the outlet of the needle and subsequently blockage of the needle usually happened when its size was smaller than $0.2 \mathrm{~mm}$. The electric field forced liquid at the outlet of needle can accelerate the evaporation of the solution in slurry. When the smaller sized needle is used the flow rate will be decreased subsequently. When the flow of slurry is insufficient to compensate for the evaporated solution the PZT slurry will dry and block the needle.

Fig. 5 shows the E-Jet printed PZT lines with variation in separations. The PZT lines had a constant width of $100 \mu \mathrm{m}$. The gaps between lines was $200 \mu \mathrm{m}, 100 \mu \mathrm{m}, 25 \mu \mathrm{m}$ and $5 \mu \mathrm{m}$, respectively (Fig. 5a-d), varied by the control of the X-Y movement stage. The smallest gap between lines was $5 \mu \mathrm{m}$ in this work (Fig. 5d), which is determined 
by the X-Y movement stage resolution $(5 \mu \mathrm{m}$ linear resolution for this movement stage). Smaller sized gaps can be achieved by using a higher resolution $X-Y$ movement stage. Other PZT film patterning techniques based on the film formation and subsequently etching process usually suffer from the controlling difficulty of the interaction between the etchant and the PZT. In addition, the patterned size of these techniques relies on the accuracy of the sacrificial layer pattern [21]. The etchant usually interacts with the sacrificial layer when etching the PZT film, which will result in the damage of the sacrificial layer pattern, especially for the long time etching process of PZT thick film. Therefore, there is usually a limitation of gap size using the etching based technique, for instance, the wet etching technique normally give a minimum gap size of more than $10 \mu \mathrm{m}$ [30].

In order to produce a thicker PZT structure multi-layer E-Jet printing of PZT slurry was carried out. Fig. 6a-e show the surface feature of the PZT lines after E-Jet printing of 1, 2, 3, 4 and 5 layers, respectively. The width of these lines was $150 \mu \mathrm{m}$. It was observed that the top surface of these lines presented convex feature. It is because that the big droplets mainly exist in the central area of E-jet, thus resulting in thicker in the central printing area and inducing the convex feature. This phenomenon was also observed in our previous work [31]. It can be seen that there were some pores presented in the films for one layer of PZT printing, where the substrate was not fully covered by the PZT particle. In order to cover the whole area of the substrate and make the film thicker more PZT printing layers were applied. Fig. 6f is the surface profile of the PZT lines produced at different printing layers. After one layer printing the line thickness was about $0.4 \mu \mathrm{m}$. It was $0.8,1.2,1.6$ and $2.2 \mu \mathrm{m}$ after E-Jet printing of 2, 3, 4 and 5 layers, respectively. It can also be seen that the cracks occurred on the surface after multi-layer printing. These cracks were formed after sintering and the cracks became more distinct when the number of printing layers increased. This is because cracking in thick films releases a greater proportion of stored elastic energy meaning that cracking is favoured in thicker constrained film systems. This phenomenon was also observed in the films produced using other deposition techniques such as spin coating $[32,33]$.

In order to reduce the stress generated in the multi-layer printed PZT thick film structures intermediate drying stages were introduced after every single layer E-Jet printing. During this drying stage the PZT structure was dried at $200{ }^{\circ} \mathrm{C}$ for $60 \mathrm{~s}$ and pyrolysed at $350{ }^{\circ} \mathrm{C}$ for $60 \mathrm{~s}$ using a hotplate to remove the organic components. Fig. $\mathbf{7 a}$ is the walled PZT structure after 30 layers printing with drying process. The width of the PZT wall after printing for one layer was $150 \mu \mathrm{m}$, however, after 30 layers printing the width of the PZT wall was $\sim 700 \mu \mathrm{m}$. The width of the final PZT wall was much larger than that printed initially. This is because after every single layer printing the PZT structure was removed for the drying process. After drying the PZT structure was placed back on the X-Y movement stage for the next layer printing. There will be a positioning error when the PZT structure was removed and placed back, which results in the misalignment between the substrate and the printing needle. This leads to the enlargement of the PZT structure after 30 layers printing. Further improvement with the use of higher accurate markers combined with micro-operation and micro-measurement system can help to reduce this size error. It was found that the cracks were significantly reduced by using this drying process (Fig. $7 \mathbf{b}$ ), which prove the function of this drying method. Fig. 7c and $\mathbf{d}$ are the cross-section at the central area and the surface profile of this printed PZT line, respectively. The porosity is $\sim 10 \%$ which was deduced from the scanning electron microscopy micrograph of 
the PZT structure fracture cross-section. It also can be seen that the thickness of the PZT wall was $12 \mu \mathrm{m}$.

In order to deposit a film over a large area and study the properties of the resultant film, a raster printing was used alternating between one layer with the long path in the $\mathrm{X}$ direction (step in $\mathrm{Y}$ direction) and the next with the long path in the $\mathrm{Y}$ direction (step in the $X$ direction). The travelling speed was $10 \mathrm{~mm} \mathrm{~s}^{-1}$, and the distance between two parallel paths of deposition was set to $0.1 \mathrm{~mm}$ to ensure a degree of overlap between deposited materials. The printing parameters were kept the same as the PZT structure produced in Fig. 6. A drying process was also applied to this PZT film after every single layer E-Jet printing. The drying process was the same as the PZT structure produced in Fig. 7.

Fig. 8a and $\mathbf{b}$ are the surface and cross-section of the PZT film after E-Jet printing of 34 layers over large area. The PZT film exhibited slight, sub-micrometer surface cracking (Fig. 8a) which were formed during the sintering process. The overlap printing of the PZT line can increase the film thickness compared with the single line printing. Thus, the cracks can be enhanced in this large area printing process compared with the single line printing (Fig. 7). But these cracks were non-connecting such that the top electrode deposited on the PZT surface was not disrupted. The cracks also did not extend through the entire thickness of the PZT film, as can be seen in Fig. 8b that this film was not electrically shorted. The relative permittivity $\left(\varepsilon_{\mathrm{r}}\right)$ of this film was calculated to be $\sim 233$ at $50 \mathrm{~Hz}$. The piezoelectric constant $\left(\mathrm{d}_{33}, \mathrm{f}\right)$ obtained at different poling voltages is shown in Fig. 9. The highest $d_{33}$ obtained was $66 \mathrm{pC} \mathrm{N}^{-1}$ when poled at $\sim 11 \mathrm{~V} \mathrm{\mu m}^{-1}$ at $200{ }^{\circ} \mathrm{C}$ for $5 \mathrm{~min}$. The values of $\mathrm{d}_{33}$ and $\varepsilon_{\mathrm{r}}$ quoted by the manufacturer for Pz26 (bulk PZT) is $290 \mathrm{pC} \mathrm{N}^{-1}$ and 1300, respectively. The $\mathrm{d}_{33}$ and $\varepsilon_{\mathrm{r}}$ obtained in this work are still lower than the bulk PZT material (Pz26). This is mainly due to the existence of residual pores and cracks, and different grain sizes in the film as well as the presence of the rigid substrate constraining the film. However, these values are comparable to the composite PZT films produced by the screen printing and spin coating [34, 35].

\section{Conclusions}

The formation of PZT thick film micro-scale structures using E-Jet printing technique was demonstrated in this paper. The PZT micro-scale structures were formed with the absence of additional materials removing process such as wet and dry etching. The effect of the ball-milling time on the PZT particle size was examined. The PZT particle size was reduced from $0.8 \mathrm{~mm}$ to $0.2 \mathrm{~mm}$ when it was ball-milled for $40 \mathrm{~h}$. The ball-milling of PZT sol and PZT powder provided stable slurry which is suitable for the printing. The PZT lines with width variations were fabricated using E-Jet printing technique at different working distances. The line width was decreased from $200 \mu \mathrm{m}$ to $80 \mu \mathrm{m}$ when the working distance was reduced from $0.5 \mathrm{~mm}$ to $0.3 \mathrm{~mm}$. The PZT lines with gap variations from $5 \mu \mathrm{m}$ to $200 \mu \mathrm{m}$ were also printed by the control of the X-Y movement stage. It was observed that cracks occurred in the PZT structures when multi-layer E-Jet printing was applied. This cracking phenomenon can be relieved by the use of an intermediated drying process. A walled PZT micro-scale structures with a thickness of $12 \mu \mathrm{m}$ was produced by 30 layers E-Jet printing. The piezoelectric coefficient $\left(\mathrm{d}_{33, \mathrm{f}}\right)$ of $66 \mathrm{pC} \mathrm{N}^{-1}$ and relative permittivity $\left(\varepsilon_{\mathrm{r}}\right)$ of 233 were obtained for this E-jet printed PZT film structure, which are comparable with those obtained in our previous work and reported in literature with similar micro-scale structures. 


\section{Acknowledgements}

This research is supported by National Natural Science Foundation of China (No. 51475081, 61340052), Science Fund for Creative Research Groups of NSFC (51321004), State Education Ministry and State Key Development Program for Basic Research of China (grant 2011CB013105) and Scientific Research Fund of Liaoning Provincial Education Department (L2013036). 


\section{References}

1. Setter N. Electroceramics: looking ahead. Journal of the European Ceramic Society 2001; 21: 1279-93.

2. Tadigadapa S, Mateti K. Piezoelectric MEMS sensors: state-of-the-art and perspectives. Measurement Science \& Technology 2009; 20: 092001.

3. Muralt P. Recent progress in materials issues for piezoelectric MEMS. Journal of the American Ceramic Society 2008; 91: 1385-96.

4. Scott JF, Dearaujo CAP. Ferroelectric memories. Science 1989; 246: 1400-5.

5. Pérez de la Cruz J. Piezoelectric Thick Films: Preparation and Characterization. In: Nazmul Islam, editors. Microelectromechanical Systems and Devices, Texas: InTech; 2012, p. 281-304.

6. Hindrichsen CG, Lou-Moller R, Hansen K, Thomsen EV. Advantages of PZT thick film for MEMS sensors. Sensors and Actuators A-Physical 2010; 163: 9-14.

7. Pickwell AJ, Dorey RA, Mba D. Development of a Thick Film PZT Foil Sensor for Use in Structural Health Monitoring Applications. IEEE Transactions on Ultrasonics, Ferroelectrics and Frequency Control 2013; 60: 373-9.

8. Zawada T, Hansen K, Lou-Moeller R. High-performance piezoelectric thick film based energy harvesting micro-generators for MEMS. Procedia Engineering 2010; 5: 1164-67.

9. Gebhardt S, Seffner L, Schlenkrich F, Schonecker A. PZT thick films for sensor and actuator applications. Journal of the European Ceramic Society 2007; 27: 4177-80.

10. Abellard AP, Kuscer D, Gregoire JM, Lethiecq M. Lead Zirconate Titanate-Based Thick Films for High-Frequency Focused Ultrasound Transducers Prepared by Electrophoretic Deposition. IEEE Transactions on Ultrasonics, Ferroelectrics and Frequency Control 2014; 61: 547-56.

11. Zhou QF, Chan HLW, Choy CL. Conducting lanthanum nickel oxide as electrodes for lead zirconate titanate films. Thin Solid Films 2000; 375: 87-90.

12. Le Dren S, Simon L, Gonnard P, Troccaz M, Nicolas A. Investigation of factors affecting the preparation of PZT thick films. Materials Research Bulletin 2000; 35: 2037-45.

13. Ferrari V. Printed thick-film piezoelectric and pyroelectric sensors. In: Prudenziati M, Hormadaly J, editors. Printed films, UK: Woodhead Publishing Limited; 2012, p. 221-58.

14. Han G, Ryu J, Yoon WH, Choi JJ. Effect of Film Thickness on the Piezoelectric Properties of Lead Zirconate Titanate Thick Films Fabricated by Aerosol Deposition. Journal of the American Ceramic Society 2011; 94: 1509-13.

15. Inoue $\mathrm{T}$, Kobayashi $\mathrm{M}$. $\mathrm{PbTiO} 3 / \mathrm{Pb}(\mathrm{Zr}, \mathrm{Ti}) \mathrm{O}-3$ sol-gel composite for ultrasonic transducer applications. Japanese Journal of Applied Physics 2014; 53: 07KC11-1-4.

16. Zhou QF, Lau ST, Wu DW, Shung KK. Piezoelectric films for high frequency ultrasonic transducers in biomedical applications. Progress in Materials Science 2011; 56: 139-74. 
17. Lou-Moeller R, Hindrichsen CC, Thamdrup LH, Bove T. Screen-printed piezoceramic thick films for miniaturised devices. Journal of Electroceramics 2007; 19: 333-8.

18. Xu R, Lei A, Dahl-Petersen C, Hansen K. Screen printed PZT/PZT thick film bimorph MEMS cantilever device for vibration energy harvesting. Sensors and Actuators A-physical 2012; 188: 383-8.

19. Miller RA, Bernstein JJ. A novel wet etch for patterning lead zirconate-titanate (PZT) thin-films. Integrated Ferroelectrics 2000; 29: 225-31.

20. Dorey RA, Whatmore RW. Electroceramic Thick Film Fabrication for MEMS. Journal of Electroceramics 2004; 12: 19-32.

21. Dorey RA, Rocks S, Dauchy F, Navarro A. New Advances in Forming Functional Ceramics for Micro Devices. Advances in Science and Technology 2006; 45: 2440-47.

22. Park JC, Hwang S, Kim JM, Kim JK, Yun YH, Shim KB, Cho H. Comparison of chlorine- and fluorine-based inductively coupled plasmas for the dry etching of PZT films. Journal of Ceramic Processing Research 2009; 10: 700-4.

23. Dorey RA. Ceramic Thick Films for MEMS and Microdevices. 1st ed. Netherlands: Elsevier; 2011.

24. Smith DPH. The electrohydrodynamic atomization of liquids. IEEE Transactions on Industry Applications 1986; 22: 527-35.

25. Jayasinghe SN, Edirisinghe MJ. Electrically forced jets and microthreads of high viscosity dielectric liquids. Journal of Aerosol Science 2004; 35: 233-43.

26. Wang X, Zheng GF, He GQ, Wei J. Electrohydrodynamic direct-writing ZnO nanofibers for device applications. Materials Letters 2013; 109: 58-61.

27. Duan HX, Li C, Yang WW, Lojewski B. Near-Field Electrospray Microprinting of Polymer-Derived Ceramics. Journal of Microelectromechanical Systems 2013; 22: 1-3.

28. Lee DY, Yu JH, Shin YS, Park D, Yu TU, Hwang J. Formation of Ceramic Nanoparticle Patterns Using Electrohydrodynamic Jet Printing with Pin-to-Pin Electrodes. Japanese Journal of Applied Physics 2008; 47:1723-5.

29. Wang D, Rocks SA, Dorey RA. Electrohydrodynamic atomization deposition of PZT sol-gel slurry and sol infiltration on the films. Journal of the European Ceramic Society 2012; 32: 1651-58.

30. Dauchy FM, Dorey RA. Patterned crack-free PZT thick films for micro-electromechanical system applications. International Journal of Advanced Manufacturing Technology 2007; 33: 86-94.

31. Wang DZ, Edirisinghe MJ, Jayasinghe SN. Solid freeform fabrication of thin-walled ceramic structures using an electrohydrodynamic jet. Journal of the American Ceramic Society 2006; 89:1727-9.

32. Dauchy FM, Dorey RA. Patterned High Frequency Thick Film MEMS Transducer. Integrated Ferroelectrics 2007; 90: 42-52.

33. Zhao $\mathrm{MH}, \mathrm{Fu} \mathrm{R}$, Lu D, Zhang TY. Critical thickness for cracking of $\mathrm{Pb}\left(\mathrm{Zr}_{0.53} \mathrm{Ti}_{0.47}\right) \mathrm{O}_{3}$ thin films deposited on $\mathrm{Pt} / \mathrm{Ti} / \mathrm{Si}(100)$ substrates. Acta Materialia 2002; 50: 4241-54. 
34. Dorey RA, Whatmore RW, Beeby SP, Torah RN, White NM. Screen printed PZT composite thick films. Integrated ferroelectrics 2004; 63: 601-4.

35. Wang ZH, Miao JM, Zhu WG. Piezoelectric thick films and their application in MEMS. Journal of the European Ceramic Society 2007; 27: 3759-64. 


\section{List of table and figure captions}

Table 1. Component of the PZT slurry and ball-milling parameters.

Table 2. Properties of the PZT slurry.

Fig. 1. Schematic diagram (a) and photograph (b) of E-Jet printing equipment.

Fig. 2. Scanning electron microscope micrographs showing the PZT powder before ball-milling (a) and after ball-milling at different times: (b) $10 \mathrm{~h}$, (c) $20 \mathrm{~h}$, (d) $30 \mathrm{~h}$ and (e) $40 \mathrm{~h}$; (f) is the PZT particle size distribution after ball-milled of $40 \mathrm{~h}$.

Fig. 3. Photograph showing the PZT slurry without ball-milling (a) and with ball-milling for $40 \mathrm{~h}(\mathrm{~b})$.

Fig. 4. Scanning electron microscope micrographs showing the PZT lines produced using E-Jet printing at different working distances: (a, b, c) $0.5 \mathrm{~mm}$, (d) $0.45 \mathrm{~mm}$, (e) $0.35 \mathrm{~mm}$ and (f) $0.3 \mathrm{~mm}$.

Fig. 5. Scanning electron microscope micrographs showing the E-Jet printed PZT lines with gap variations at a working distance of $0.35 \mathrm{~mm}$ : (a) $200 \mu \mathrm{m}$, (b) $100 \mu \mathrm{m}$, (c) $25 \mu \mathrm{m}$ and (d) $5 \mu \mathrm{m}$.

Fig. 6. Scanning electron microscope micrographs showing the surface of PZT walled structures produced using E-Jet printing with different layers: (a) 1 layer, (b) 2 layers, (c) 3 layers, (d) 4 layers and (e) 5 layers; (f) is the surface profile of the E-Jet printed PZT wall in (a-e).

Fig. 7. Scanning electron microscope micrographs showing the walled PZT thick film structure produced by 30 layers overlapping E-Jet printing with intermediate drying stages after each single layer printing: (a) top view of the PZT walled structure and its surface (b), cross-section (c) and its surface profile (d).

Fig. 8. Scanning electron microscope micrographs showing the PZT thick film produced by 34 layers raster E-Jet printing with intermediate drying stages after every raster layer printing (a) and its cross-section (b).

Fig. 9. Piezoelectric constant of the E-Jet printed PZT thick film poled at $200{ }^{\circ} \mathrm{C}$ for 5 min at different poling fields. 
Table 1.Component of the PZT slurry and ball-milling parameters

\begin{tabular}{ll}
\hline PZT powder & $10 \mathrm{~g}$ \\
PZT sol & $14.2 \mathrm{ml}$ \\
Dispersant KR 55 & $0.2 \mathrm{~g}$ \\
Milling balls & $100 \mathrm{~g}$ of $6 \mathrm{~mm}$ diameter zirconia balls \\
Milling speed (revolution) & $190 \mathrm{r} / \mathrm{min}$ \\
Milling speed (rotation) & $380 \mathrm{r} / \mathrm{min}$ \\
Milling time & $40 \mathrm{~h}$ \\
Balls/PZT ratio & $10: 1$ \\
Solid load of PZT slurry & $48.6 \%$ \\
\hline
\end{tabular}

Table 2. Properties of the PZT slurry

\begin{tabular}{ccccccc}
\hline $\begin{array}{c}\text { PZT } \\
\text { slurry }\end{array}$ & $\begin{array}{c}\text { Density } \\
\left(\mathrm{Kg} \mathrm{m}^{-3}\right)\end{array}$ & $\begin{array}{c}\text { Viscosity } \\
(\mathrm{Pa} \mathrm{s})\end{array}$ & $\begin{array}{c}\text { Surface } \\
\text { tension }\left(\mathrm{N} \mathrm{m}^{-1}\right)\end{array}$ & $\begin{array}{c}\text { Electrical } \\
\text { conductivity } \\
\left(\mathrm{S} \mathrm{m}^{-1}\right)\end{array}$ & $\begin{array}{c}\text { Relative } \\
\text { permittivity }\end{array}$ & $\mathrm{PH}$ \\
\hline \multirow{2}{*}{1502.6} & $\begin{array}{c}15.0 \times 10^{-3} \\
(\text { at a shear } \\
\left.\text { of } 836 \mathrm{~s}^{-1}\right)\end{array}$ & $2.2 \times 10^{-2}$ & $5.7 \times 10^{-3}$ & 9.7 & 4.0 \\
\hline
\end{tabular}




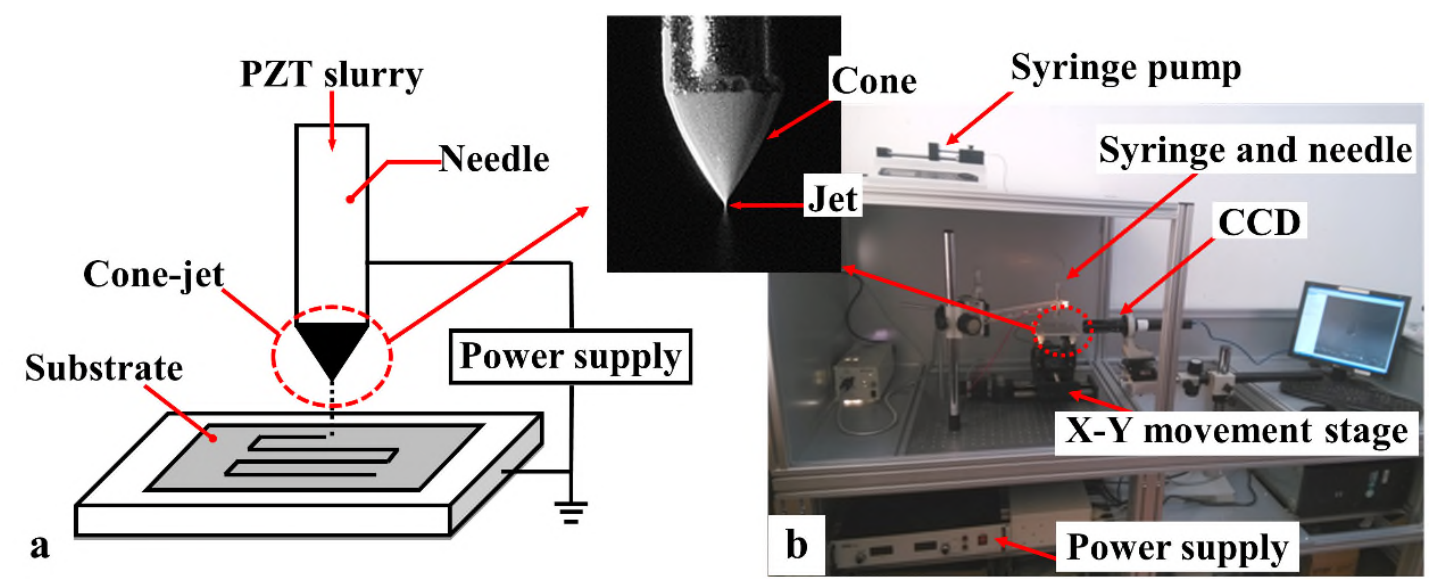

Figure 1

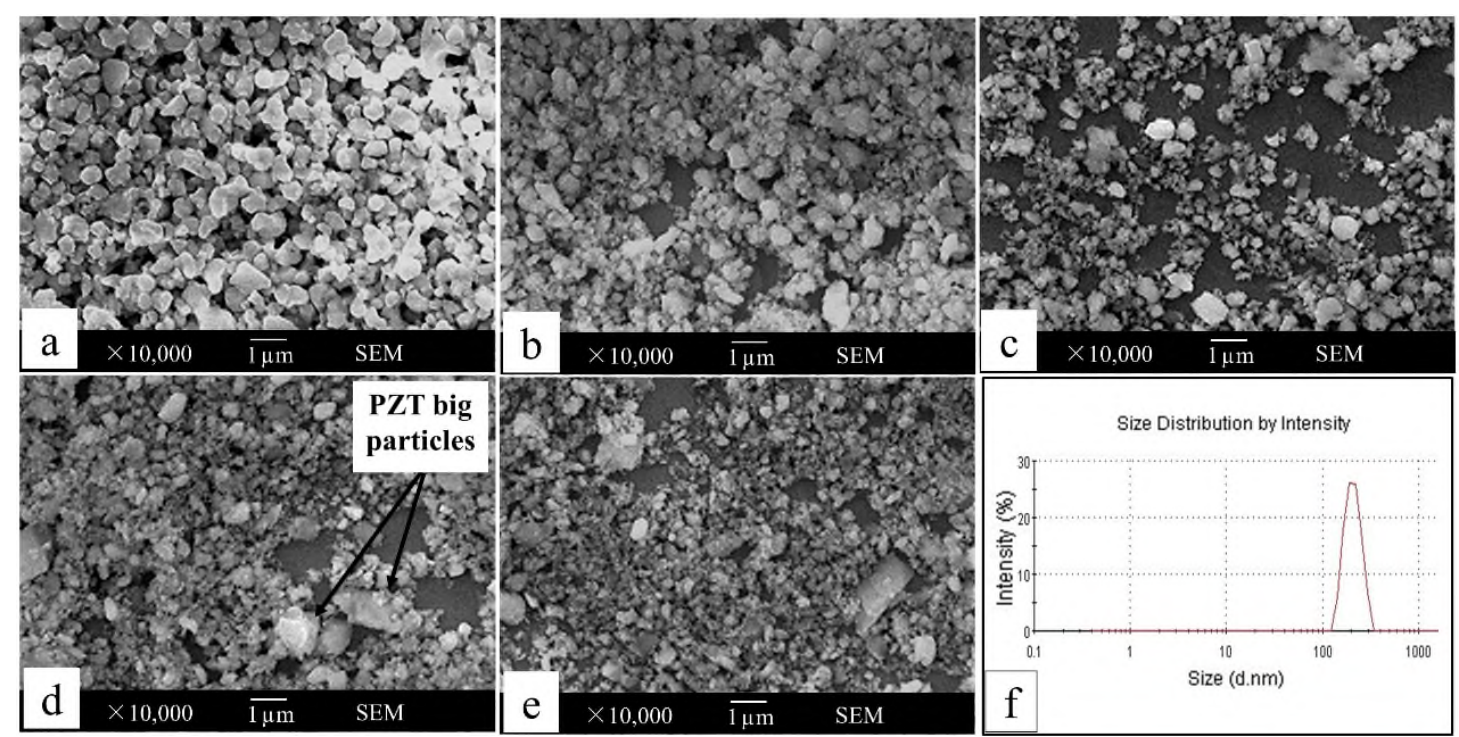

Figure 2

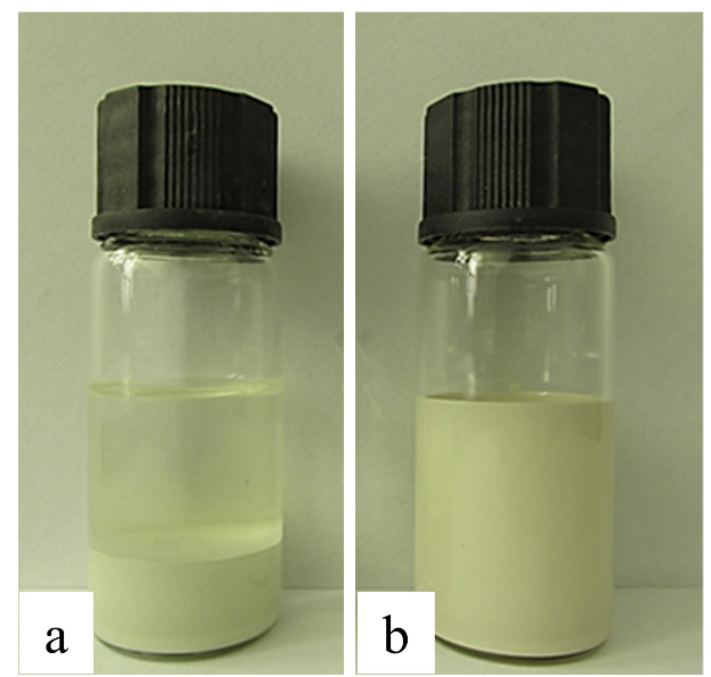

Figure 3 


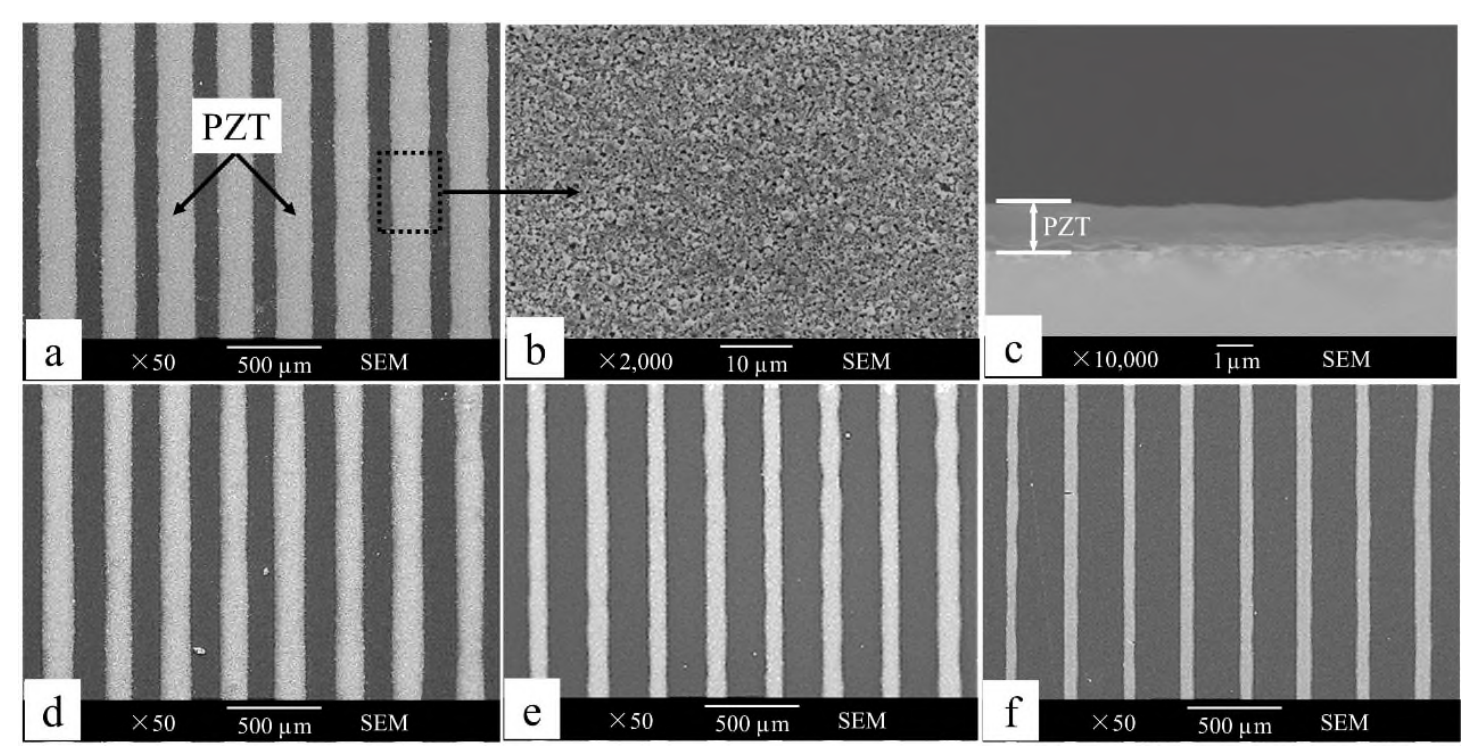

Figure 4

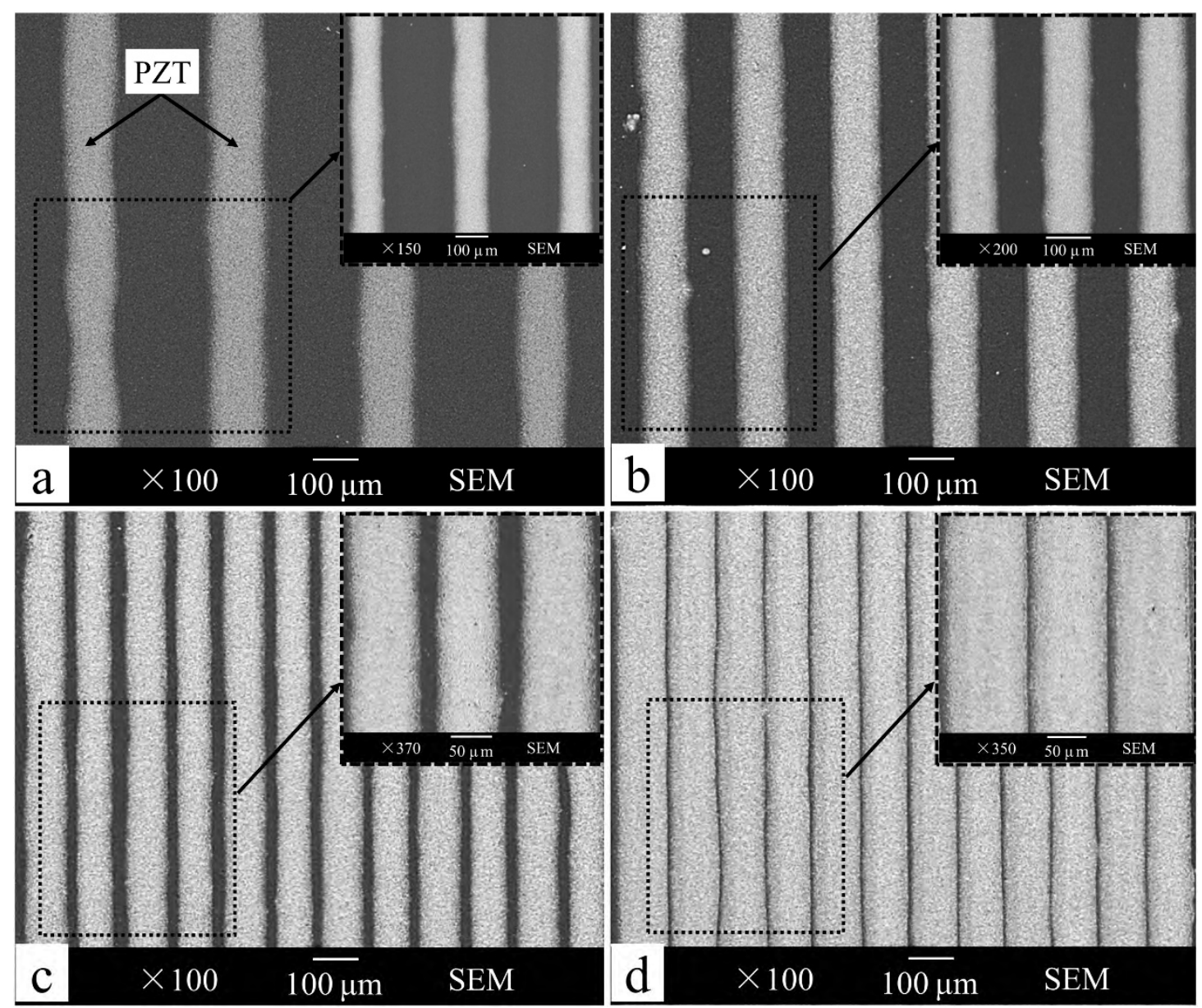

Figure 5 


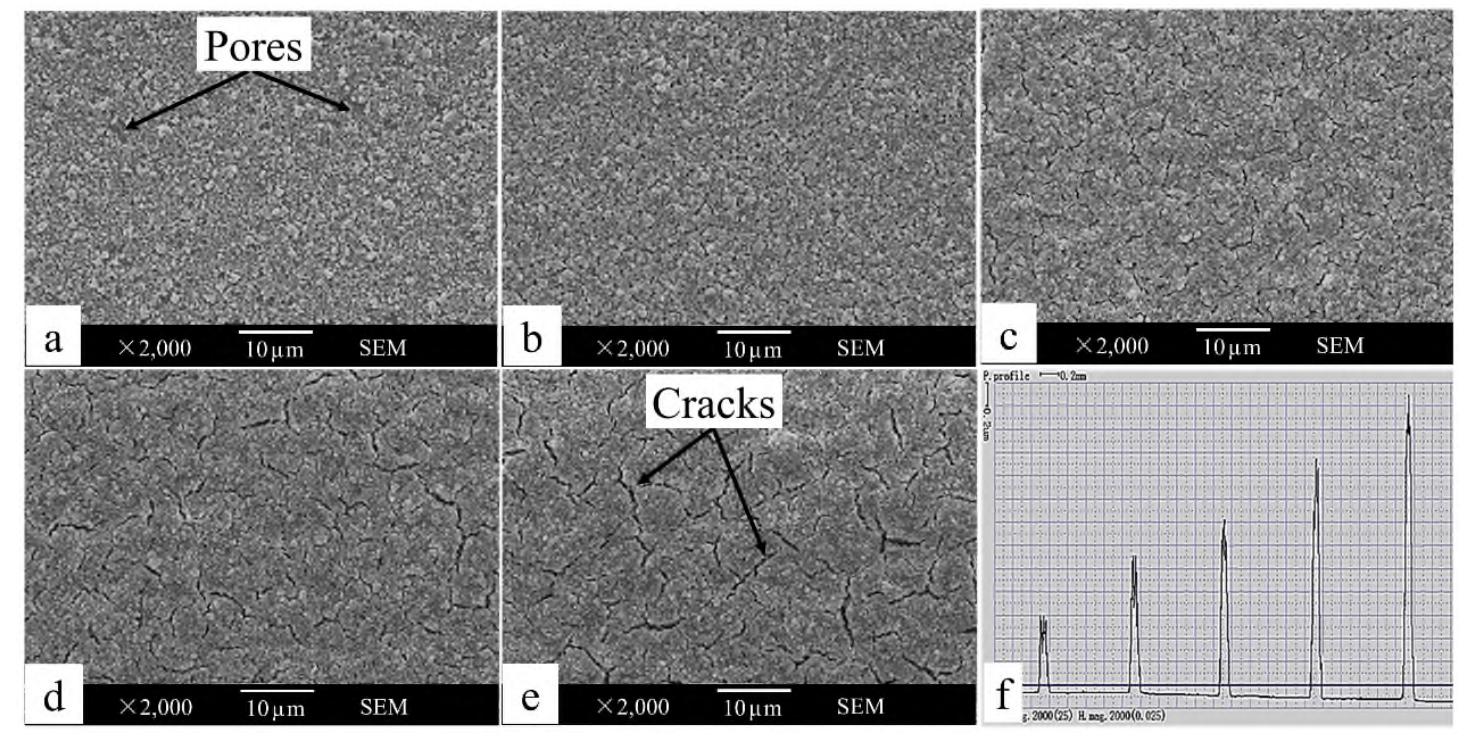

Figure 6

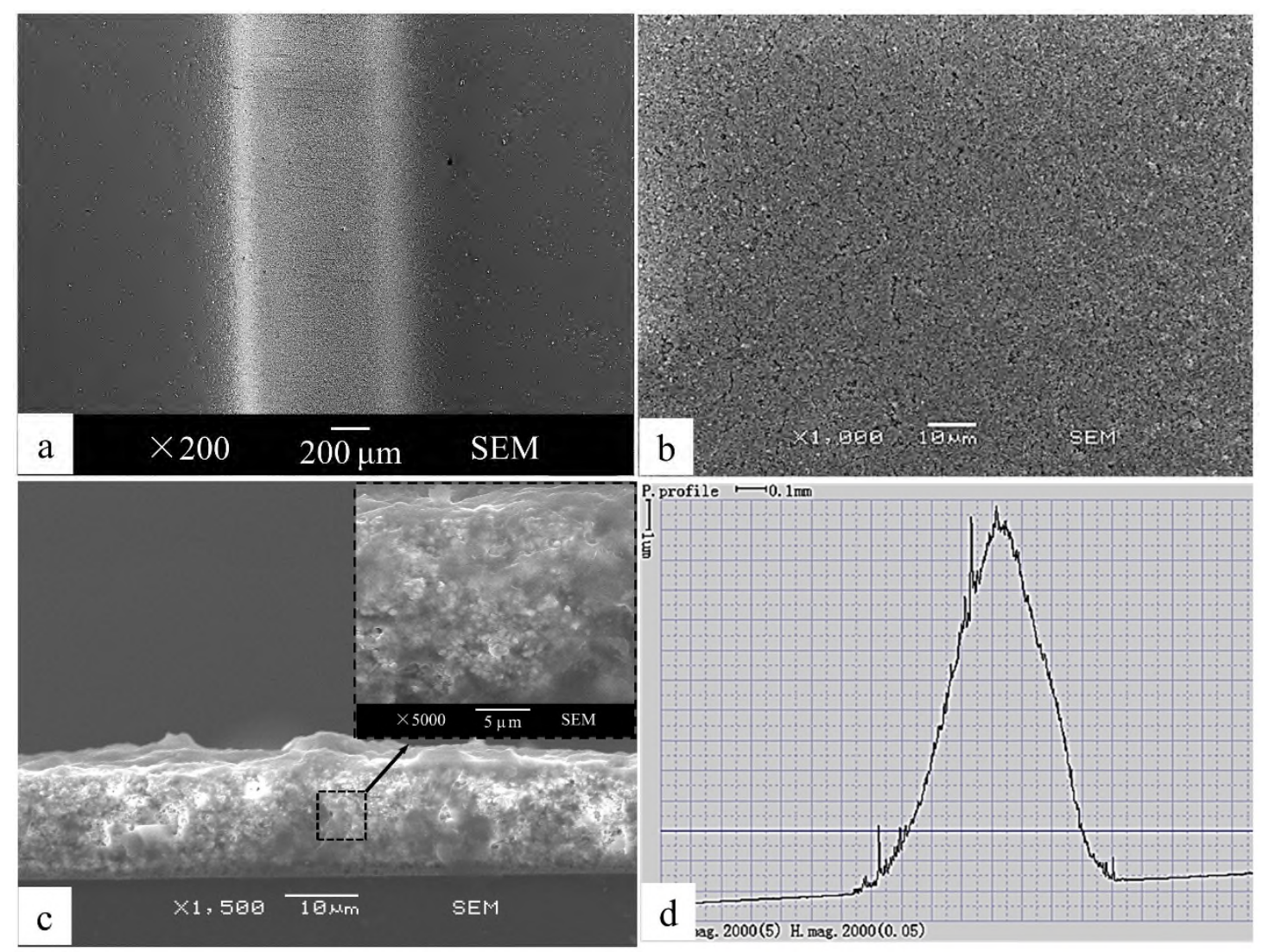

Figure 7 


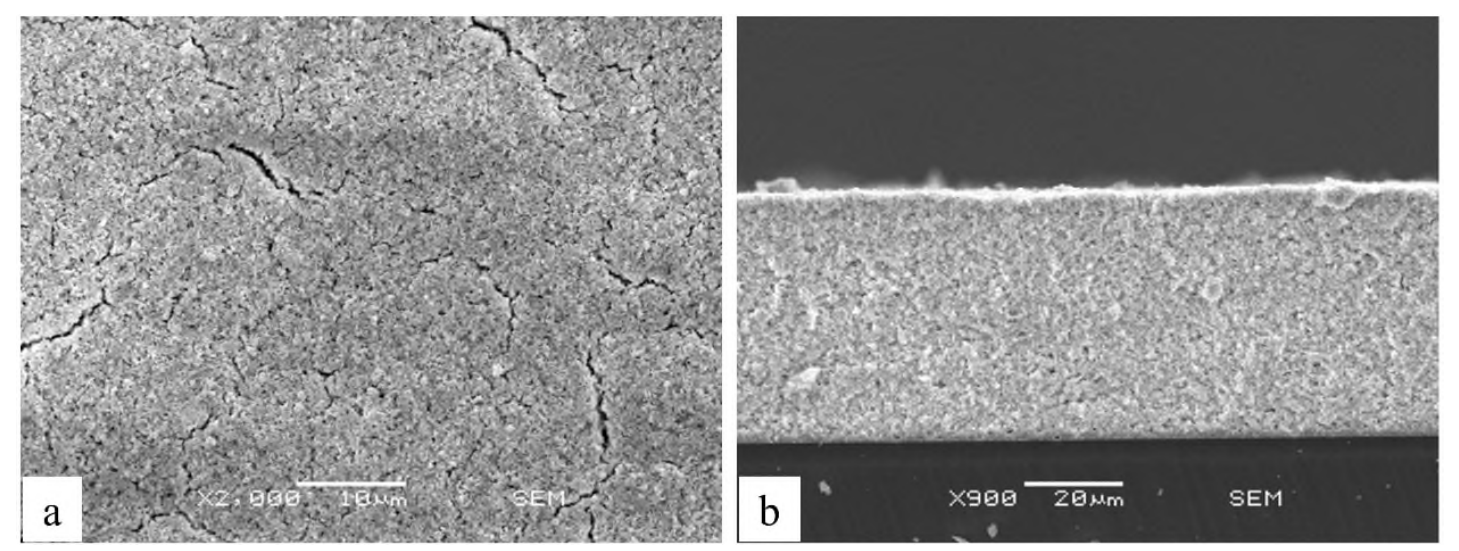

Figure 8

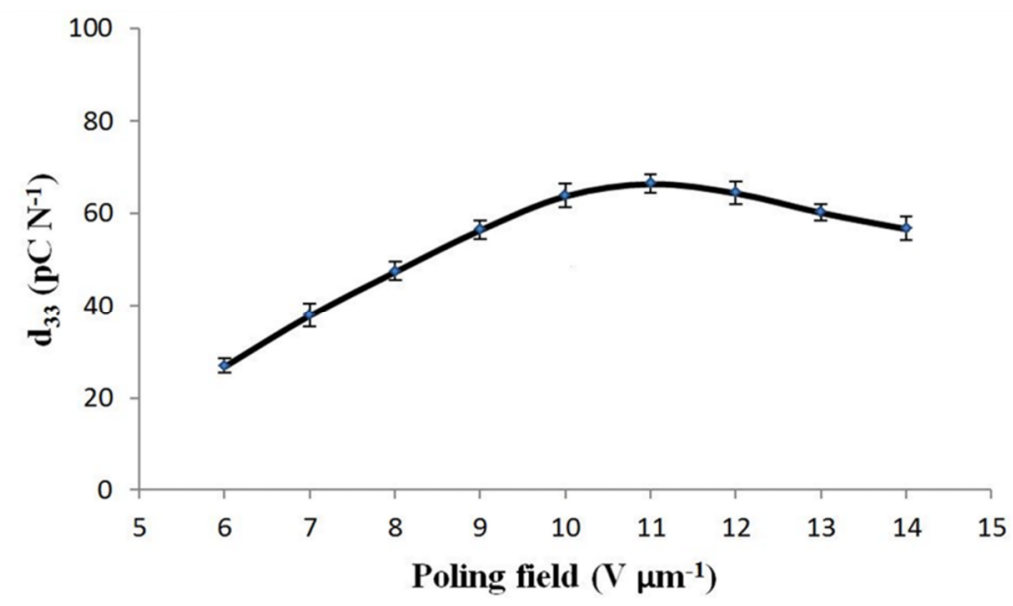

Figure 9 